\title{
Obtaining Dynamic Parameters by Using Ambient Vibration Recordings on Model of The Steel Arch Bridge
}

\author{
Azer A. Kasimzade', Sertaç Tuhta', Furkan Günday¹, Hakan Aydın* \\ ${ }^{1}$ Ondokuz Mayis University, Faculty of Engineering, Department of Civil Engineering, Atakum 55270, Samsun, Turkey \\ * Corresponding author, e-mail: hakanaydin@ilkadim.bel.tr
}

Received: 10 May 2020, Accepted: 21 January 2021, Published online: 12 February 2021

\begin{abstract}
Operational Modal Analysis (OMA) is a one of the most popular method to extract the dynamic characteristics from ambient vibration response signals. In this study, the dynamic characteristics of a model of steel arch bridge with a bolt connection constructed in a $6.10 \mathrm{~m}$ span and $1.88 \mathrm{~m}$ height laboratory were determined by finite element method and operational modal analysis methods. Firstly, finite element model was created in SAP2000 software of model steel system and dynamic characteristic were obtained numerically. Then, accelerometers were placed where the displacements are high on points of the system and dynamic characteristics were determined by operational modal analysis method. The aim of this study is to obtain the dynamic parameters (frequency, damping ratio, mode shapes) of the model of the steel arch bridge accurately and reliably by operational modal analysis method by making use of ambient vibrations in the laboratory conditions. For this purpose, analytical analysis of the model of the steel arch bridge with finite element method and the dynamic parameters obtained as a result of the operational modal analysis of the model steel arch bridge were compared. Also, the modal assurance criterion (MAC) was used. Good compatibility was recognized between the results obtained for experimental and numerical procedures in terms of both the natural frequency and the mode of vibration. At the end of this study, reasonable correlation is obtained between mode shapes, frequencies and damping ratios. Analytical and Operational modal frequencies differences between $0.139 \%-7.170 \%$.
\end{abstract}

Keywords

model steel arch bridge, OMA, SSI, Finite Element Analysis, ambient vibrations

\section{Introduction}

Evaluations on the structural condition of the bridges are mostly made on the basis of observation and project data. Limited evaluations made by subjective evaluation and observational methods can be misleading in some cases. A healthy-looking bridge can be in critical condition with an invisible problem. (e.g. a fatigue crack) A bridge that looks very old and problematic may be structurally intact. Among the measurement-based methods, the most commonly used method is dynamic measurements. Dynamic readings made by accelerometers can simply be thrown into the frequency space to obtain the dominant period or frequencies and compare them with the analytical model to be established.

However, it is often encountered that the frequencies of the bridge modes are close to each other, or that the twisting and bending modes are displaced. Comparing the analytical model based on frequency without knowing the mode shapes, many uncertainties and possible errors bears the risk.
Experimental measurement methods are frequently used to determine the dynamic characteristics of engineering structures. These methods can be grouped into three groups as forced vibration tests, free vibration tests and environmental vibration tests. Structure in forced vibration tests; it is stimulated with the help of a vibrator. The most important disadvantage of this method is that the essential activities in the structure will be interrupted during the measurement. Environmental vibration tests are used for effects such as wind, traffic, human movement and waves. During the measurement, daily activities in the structure can continue in this way. Natural frequencies and the corresponding mode shapes and damping ratios are the dynamic characteristics of the structures. These characteristics can be determined by experimental modal analysis methods. The damping rates occur within the material of the system subjected to motion and between its elements. It occurs as a measure of internal friction or 
energy consumed. In the literature researches, many studies using the Operational Modal Analysis (OMA) method have been reached. Natke and Cempel [1], Matsumoto et al. [2], Kvåle et al. [3], Cantieni [4], Gentile [5] etc. authors have conducted studies on steel bridges.

There are some studies in the literature regarding the determination of steel bridge modal parameters constructed in the laboratory. Sanayei and DiCarlo [6] made the finite element model updating of a scaled bridge model using the measured response data. Four impact hammers and eight accelerometer locations were pointed in the measurements. Excitations and measured responses were used to identify the few natural frequency mode shapes. Yang [7] modeled the long span bridge model under laboratory conditions to determine the seismic response involving the spatial variation of seismic waves in his doctoral thesis. Both shake table model tests for experimental identification and Finite Element Analysis for analytical identification were carried out. Natke and Cempel made damage assessment studies on a steel bridge by using the changes in frequency and mode shapes. They conducted a structural health monitoring study based on vibration on the diagonal elements of a steel truss bridge. At the end of the study, they found improvements in diagonal elements containing cracks and notches. Aydin [8] analyzed the mathematical model of a model steel bridge using the system identification method in this study. Artificial Neural Networks (ANN), which is a system identification method, was used as a method, and he successfully defined the system of the model steel bridge with the ANN method at a rate of $90 \%$.And also he reached the results of ANN approach can provide a very useful and accurate tool to solve the problem in modal identification studies. Matsumoto et al. conducted a field study of structural health monitoring based on vibration on the diagonal elements of a steel truss bridge. At the end of their work, they improved the diagonal elements containing cracks and notches. Wei-Xin Ren et al. [9] presents the experimental and analytical modal analysis of a steel-girder arch bridge. Both the peak picking method in the frequency domain and the stochastic subspace identification method in the time domain are used for the output-only modal identification in this paper. As a result the stochastic subspace identification method is provided better mode shapes. The three-dimensional finite element models were constructed and an analytical modal analysis is then performed to generate natural frequencies and mode shapes in the three-orthogonal directions.
General characteristics of structural response (appropriate frequency, displacement, velocity, acceleration rungs), suggested measuring quantity (such as velocity or acceleration) depends on the type of vibrations. This structure response characteristics gives a general idea of the preferred quantity and its rungs to be measured. The modal parameter identification using output-only measurements presents a challenge that needs the use of special identification techniques, which can deal with very small magnitudes of ambient vibration contaminated by noise without the knowledge of input forces. A new structural identification tool is proposed to identify the modal properties of structures. At last, after collecting modal responses from the available sensors, the mode shape vector for each of the decomposed modes in the system is identified from all obtained modal response data [10-18]. Over the past decades, the technique of experimental modal parameter identification of civil engineering structures has developed very fast. The benchmark study has been carried out to compare modal parameter identification techniques for evaluating the dynamic characteristics of a real building on operation conditions from ambient vibration data. In fact, the mathematical background of output-only modal parameter identification methods is often very similar. The difference is often due to implementation aspects such as data reduction, type of equation solvers, sequence of matrix operations, etc. Consequently, the question arises to compare those analysis techniques with regard to full-scale structures.

By using the Operational Modal Analysis method, which is based on the principle of measuring the reactions created by environmental impacts in the structure, this study will be carried out in laboratory conditions, and a short-term measurement will be taken to realize the behavior of the steel arch bridge model. In this study, the dynamic characteristics of the model steel arch bridge will be determined by experimental methods. The modal properties of the model steel arch bridge were computed using analytical approach for a comparison with the experimental modal frequencies. According to the seismic damage types of steel bridges, the dynamic stability and bearing capacity, the post-earthquake serviceability and reparability, low-cycle fatigue are some important contents for seismic safety checking [19-22]. Operational modal analysis is being widely used in aerospace, mechanical and civil engineering [23-37]. Common research fields include optimal design and rehabilitation under dynamic loads, structural health monitoring, modification and control of dynamic response and analytical model updating [38-39]. 


\section{Method}

The Stochastic Subspace Identification Technique (SSI) is a time-domain method that works directly with raw time data without the need to convert them to correlations or spectra. The stochastic subspace identification algorithm defines state space matrices based on measurements using robust digital techniques. When the mathematical definition of construction (state-space model) is found, modal parameters are simple to determine. The theoreticaly distances is given in $[20,25]$. The model of the vibrational structures can be described by a series of linear, constant-coefficient and second-order differential equations [29];

$m \ddot{u}(t)+c \dot{u}(t)+k u(t)=d f(t)$,

Where $\boldsymbol{m}, \boldsymbol{c}, \boldsymbol{k}$ are the mass, damping and stiffness matrices, $\boldsymbol{f}(\boldsymbol{t})$ is the stimulation force, and $\boldsymbol{u}(\boldsymbol{t})$ is the displacement vector at continuous time $t . d$ is an input influence matrix, characterizing the locations and type of known inputs $\boldsymbol{f}(\boldsymbol{t})$. The state-space model is derived from the control theory, but it also appears in mechanical-civil engineering to calculate the modal parameters of a dynamic structure with a general viscous damping model [23]. The motion Eq. (1) is transformed into space-space, which is the first of the first-order equations, that is, the system is regarded as a continuous-time state-space model.

$$
\begin{aligned}
& \dot{\boldsymbol{z}}(\boldsymbol{t})=\boldsymbol{A}_{c} \boldsymbol{z}(\boldsymbol{t})+\boldsymbol{B}_{c} \boldsymbol{f}(\boldsymbol{t}) \\
& \boldsymbol{A}_{c}=\left[\begin{array}{cc}
0 & \boldsymbol{I} \\
-\boldsymbol{m}^{-1} \boldsymbol{k} & -\boldsymbol{m}^{-1} \boldsymbol{c}
\end{array}\right] \\
& \boldsymbol{B}_{c}=\left[\begin{array}{c}
0 \\
m^{-1} \boldsymbol{d}
\end{array}\right] \\
& \boldsymbol{z}(\boldsymbol{t})=\left[\begin{array}{l}
\boldsymbol{u}(\boldsymbol{t}) \\
\dot{\boldsymbol{u}}(\boldsymbol{t})
\end{array}\right]
\end{aligned}
$$

Where $\boldsymbol{A} c$ is the state matrix, $\boldsymbol{B} c$ is the input matrix and $\boldsymbol{z}(\boldsymbol{t})$ is the state vector. The number of elements of the state space vector is the number of arguments needed to describe the state of the system. Assuming that the measurements are evaluated only at one sensor position and that these sensors are displacement, velocity and acceleration transducers, and the observation equation is

$$
\boldsymbol{y}(\boldsymbol{t})=\boldsymbol{C}_{a} \ddot{u}(\boldsymbol{t})+\boldsymbol{C}_{v} \dot{u}(\boldsymbol{t})+C_{d} u(t),
$$

where $\boldsymbol{y}(\boldsymbol{t})$ are the outputs, and $\boldsymbol{C}_{a}, \boldsymbol{C}_{v}, \boldsymbol{C}_{d}$ are the output matrices for acceleration, velocity, displacement. With this definitions

$$
\begin{aligned}
& \boldsymbol{C}=\left[\boldsymbol{C}_{d}-\boldsymbol{C}_{a} \boldsymbol{m}^{-1} \boldsymbol{k}, \boldsymbol{C}_{v}-\boldsymbol{C}_{a} \boldsymbol{m}^{-1} \boldsymbol{c}\right] \\
& \boldsymbol{D}=\boldsymbol{C}_{a} \boldsymbol{m}^{-1} \boldsymbol{d}
\end{aligned}
$$

Equation (4) can be transformed into:

$$
y(t)=C z(t)+D u(t),
$$

where $\boldsymbol{C}$ is the output matrix and $\boldsymbol{D}$ is the direct transmission matrix. Equations (2) and (6) form a continuous-time deterministic state-space model. Continuous time means that the expressions can be evaluated at each time instant $\boldsymbol{t} \in \mathbb{R}$ and deterministic means that the input-output quantities $\boldsymbol{u}(\boldsymbol{t}), \boldsymbol{y}(\boldsymbol{t})$ can be measured exactly. Of course, this is not realistic: measurements are available at discrete time instants $\boldsymbol{k} \Delta \boldsymbol{t}, \boldsymbol{k} \in \mathbb{N}$ with $\Delta \boldsymbol{t}$, sample time and noise always influence the data. After the example, the state-space model looks like this:

$$
\begin{aligned}
& \boldsymbol{z}_{k+1}=\boldsymbol{A} \boldsymbol{z}_{k}+\boldsymbol{B} \boldsymbol{u}_{k}, \\
& \boldsymbol{y}_{k}=\boldsymbol{C} \boldsymbol{z}_{k}+\boldsymbol{D} \boldsymbol{u}_{k},
\end{aligned}
$$

Where $\boldsymbol{z}_{k}=\boldsymbol{z}(\boldsymbol{k} \Delta \boldsymbol{t})$ is the discrete-time state vector, is the process noise due to disturbance and modeling imperfections; $v_{k}$ is the measurement noise due to sensors' inaccuracies; it includes stochastic noise and we obtain the following discrete-time combined deterministic-stochastic state-space model:

$$
\begin{aligned}
& \boldsymbol{z}_{k+1}=\boldsymbol{A} \boldsymbol{z}_{k}+\boldsymbol{B} \boldsymbol{u}_{k}+\boldsymbol{w}_{k}, \\
& \boldsymbol{y}_{k}=\boldsymbol{C} \boldsymbol{z}_{k}+\boldsymbol{D} \boldsymbol{u}_{k}+\boldsymbol{v}_{k} .
\end{aligned}
$$

$\boldsymbol{w}_{k}, \boldsymbol{v}_{k}$ vectors are non-measurable, but they assume that there is zero average and white noise. If this white noise hypothesis is violated, in other words if the input contains also some dominant frequency components in addition to white noise, these frequency components are indistinguishable from the system's own frequencies and appear as eigenvalues of the system matrix $\boldsymbol{A}$.

$$
\boldsymbol{E}\left[\left(\begin{array}{c}
\boldsymbol{w}_{p} \\
\boldsymbol{v}_{p}
\end{array}\right) \quad\left(\begin{array}{ll}
\boldsymbol{w}_{q}^{T} & \boldsymbol{v}_{q}^{T}
\end{array}\right)\right]=\left(\begin{array}{cc}
\boldsymbol{Q} & \boldsymbol{S} \\
\boldsymbol{S}^{T} & \boldsymbol{R}
\end{array}\right) \delta_{p q},
$$

where $\boldsymbol{E}$ is the expected value operator and $\delta_{p q}$ is the Kronecker delta. Vibration information available in structural health monitoring (SHM) is often the reaction of a structure induced by operational inputs, some of which are unmeasured inputs. Due to the lack of input information it is not possible to distinguish deterministic input $\boldsymbol{u}_{k}$ from the noise terms $\boldsymbol{w}_{k}, \boldsymbol{v}_{k}$ in [2]. If the deterministic input term $\boldsymbol{u}_{k}$ is modeled by the noise terms $\boldsymbol{w}_{k}, \boldsymbol{v}_{k}$ the discrete-time purely stochastic state-space model of a vibration structure is obtained: 
$\boldsymbol{z}_{k+1}=\boldsymbol{A} \boldsymbol{z}_{k}+\boldsymbol{w}_{k}$,

$\boldsymbol{y}_{k}=\boldsymbol{C} \boldsymbol{z}_{k}+\boldsymbol{v}_{k}$.

In Eq. (10) the operational vibration measurements provide the basis for defining the time-consuming system. The stochastic subspace method defines state space matrices based solely on output measurements and robust digital techniques.

Output only modal analysis is a type of operational modal analysis. This method aims to determine the reactions of the structure under ambient vibrations. Although it is a widely used method recently, the reliability of its results is also an important positive aspect.

In this study, output only modal analysis method was used. As is known in this method, under ambient vibrations, responses are taken from various joints of the model steel arch bridge.

\section{Description of model steel arch bridge}

The model steel bridge used in this study was designed for experimental purposes. The model used in this study made the steel bridge sample suitable for the general bridge design. During the design phase, various steel bridges in the world were examined and a design was put forward. Afterwards, a model was produced by scaling. With this design model bridge, the model steel bridge used in the study participated in the Design \& Construct 2016 competition organized by the Boğaziçi University Building Club one of Turkey's most established universities.

The bridge has a deformed arch geometry. The legs bending inwards in the direction of the long axis of the deck enabled the console operation of the end sections of the deck. In this way, the weight of the elements that cannot bear any load other than their permanent load has been reduced. 45 degree bending is provided in the feet. The profiles that continue along the axis of the deck are made of $20 \times 50 \mathrm{~mm}$ box beam profile with a thickness of $2 \mathrm{~mm}$. In the lattice beams, $4 \mathrm{~cm}$ diameter circular section profile elements with a thickness of $3 \mathrm{~mm}$ are used. Steel rod elements with a diameter of $10 \mathrm{~mm}$ are used in the Pillar and Cross connection (Diagonals) elements. Steel bridge model weight is $110 \mathrm{Kg}$.

In this study, $6.10 \mathrm{~m}$ span, $1.88 \mathrm{~m}$ height model steel arch bridge used. The model steel arch bridge is shown in Fig. 1. The bridge model has a deformed arch geometry. Bridge connections are bolted. Each bolt is tightened with a torque wrench to a constant torque value of 40 N.m. The time-dependent variation of bolt torque values also changes the modal parameters of the bridge; therefore, the torque values were checked periodically during the test period and it was observed that there was no change. M10 and M6 bolts are used as joint material in the model steel bridge. In the model steel bridge, the connection details have been checked one by one. (Fig. 2) Connection points, connection details and metric bolt tensile loads and tightening torque values of bolts were checked with torque wrench. Screw tightening and measurement process has been done. Bolt diameters, dimensions and tightening values are made using a torque wrench.

The model steel bridge of the experiment is located in the laboratory environment and away from the external effects. Thus, the desired results are obtained more clearly and healthier. The clarity and accuracy of the results and the true representation of the model play an important role in scientific studies. In this study, measurements and experiments were carried out with careful attention to all scientific procedures.

\section{Analytical modal analysis of model steel arch bridge} A finite element model was generated in SAP2000 software in Fig. 3. Bridge modeled as an absolutely rigidity (rigid diaphragm). The selected bridge is modeled as a space frame bridge with 3D elements. Model steel arch

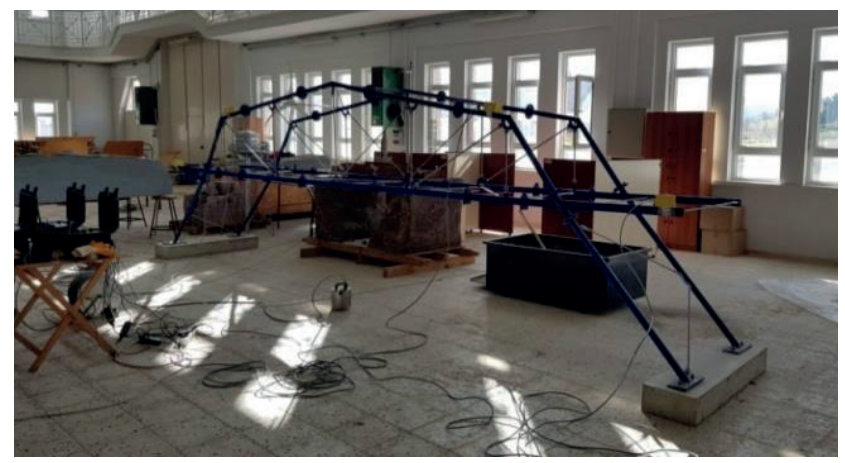

Fig. 1 Formation of model steel bridge

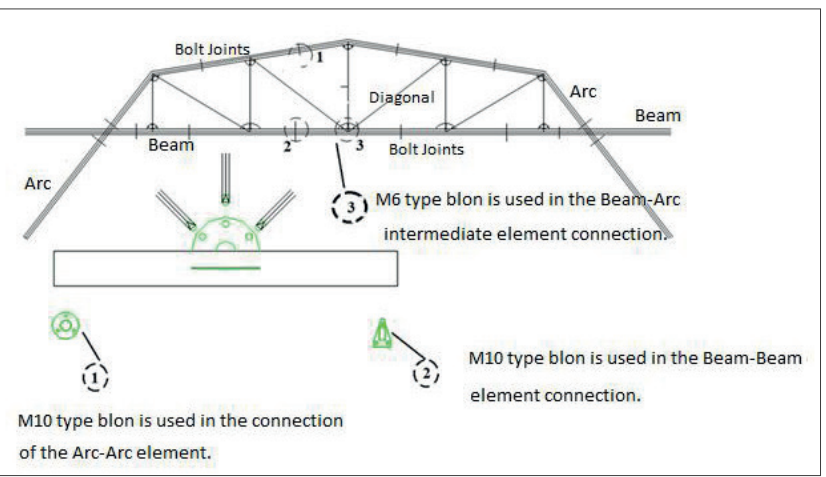

Fig. 2 Model steel bridge element connection details 
bridge is modeled using an equivalent thickness and frame elements with isotropic property. All supports are modeled as fully fixed. The members of model steel bridge are modeled as rigidly connected together at the intersection points. The model steel bridge is modeled with finite elements Fig. 3. When modeling the model steel bridge, the modulus of elasticity was taken as $E=2.0 \times 105 \mathrm{MPa}$, material density $\rho=7.85 \mathrm{~kg} / \mathrm{m}^{3}$ and Poisson's ratio $v=0.3$.

A total of 40 joints and 71 bar elements (straight diagonal-beam) were used in the model. A total of five natural frequencies of the model steel bridges are attained which range between 5 and $17 \mathrm{~Hz}$. The first five vibration mode of the model steel bridge is shown in Figs. 4-8. Analytical modal analysis results at the finite element model is shown in Table 1.

5 Operational modal analysis of model steel arch bridge Two accelerometers, one of which is three-axis and the other one, are rigidly fixed to the required nodes. While

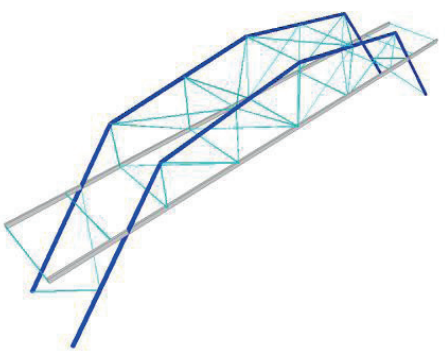

Fig. 3 Finite Element Model of model steel arch bridge

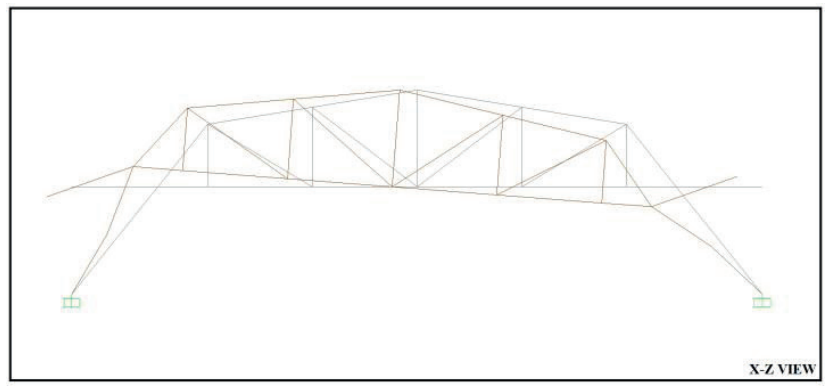

Fig. 4 1st Mode shape $(f=5.743 \mathrm{~Hz})$

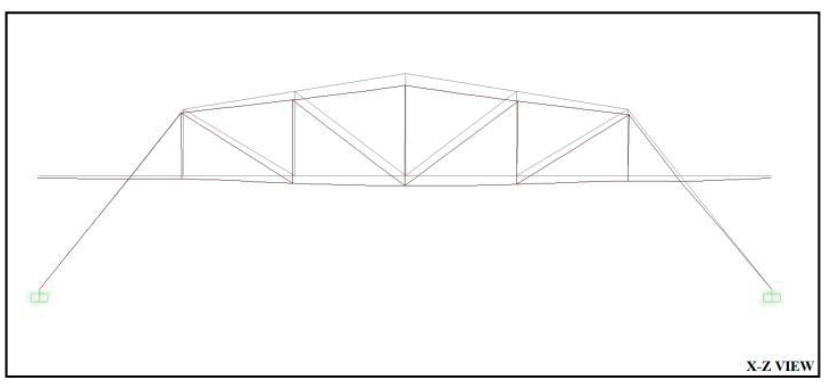

Fig. 5 2nd Mode shape $(f=11.539 \mathrm{~Hz})$

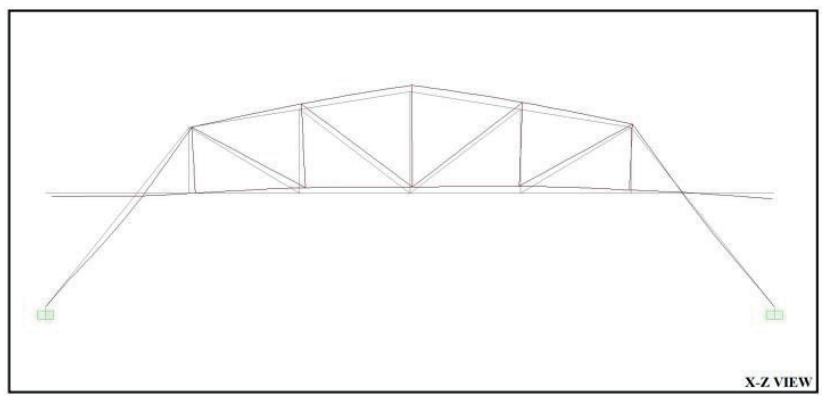

Fig. 6 3rd Mode shape $(f=17.180 \mathrm{~Hz})$

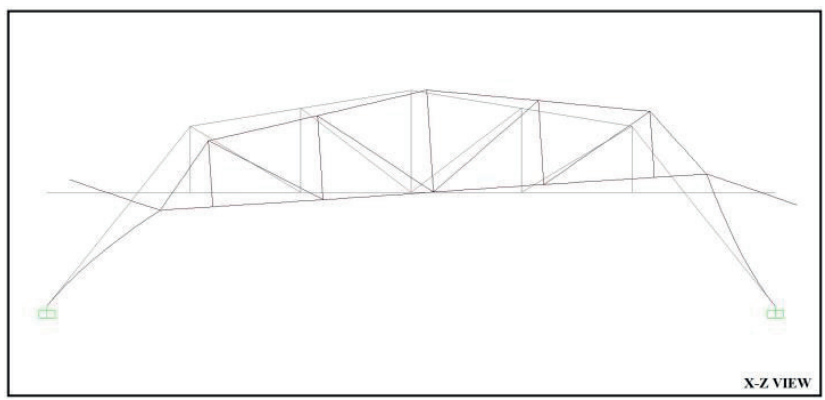

Fig.7 4th Mode shape $(f=21.097 \mathrm{~Hz})$

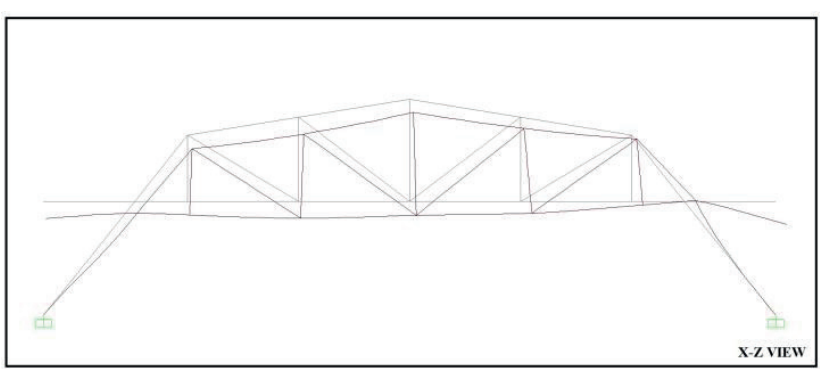

Fig. 8 th Mode shape $(f=25.799 \mathrm{~Hz})$

Table 1 Values obtained By FEA (Sap 2000)

\begin{tabular}{lccccc}
\hline Mode & 1 & 2 & 3 & 4 & 5 \\
\hline Frequency $(\mathrm{Hz})$ & 5.743 & 11.539 & 17.180 & 21.097 & 25.799 \\
\hline
\end{tabular}

the accelerometers are being placed, the spirit level is provided to place the millimetric directions to the joints. Thus, it is ensured that the errors that may occur are minimized. Placed accelerometers are fixed with strong adhesive material prevent any possible shift, displacement. The layout of the accelerometers and the reference accelerometer can be clearly seen in the (Figs. 9-10).

Natural frequencies acquired from the all measurement setup are given in Table 2 .

The uniaxial accelerometers on the right are designated as reference. Reference accelerometers are in Fig. 10.

ARTEMIS package program was used for output only modal analysis. Fig. 10 shows the accelerometer placed on the model steel bridge and the measuring device. One data 


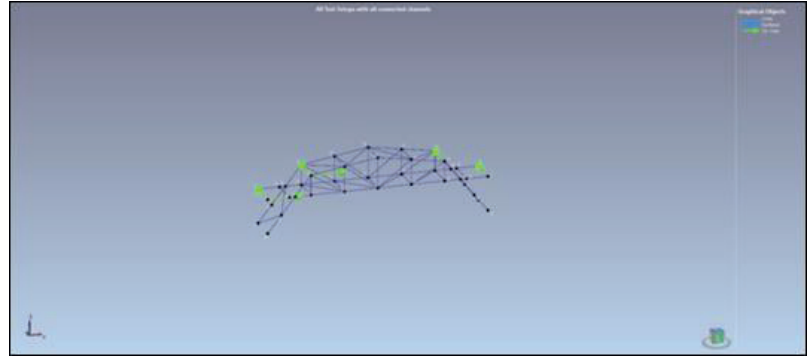

Fig. 9 The layout of the accelerometers

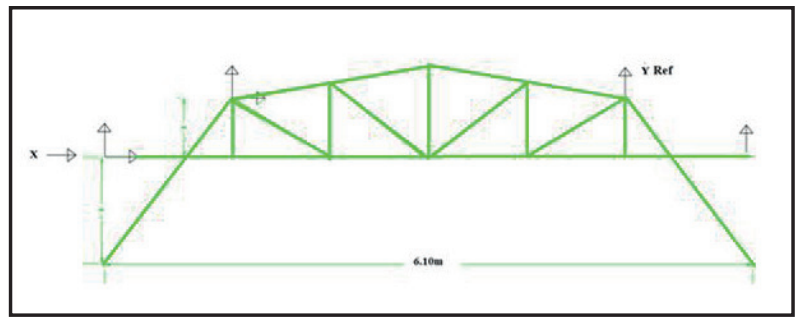

Fig. 10 Determination of reference accelerometer

Table 2 Operational modal analysis result at the model steel bridge

\begin{tabular}{lccc}
\hline MODE & Frequency $[\mathrm{Hz}]$ & Damping $[\xi]$ & Period $[\mathrm{s}]$ \\
\hline 1 & 5.751 & 0.018 & 0,174 \\
2 & 11.605 & 0.024 & 0.086 \\
3 & 17.219 & 0.020 & 0.058 \\
4 & 21.151 & 0.026 & 0.047 \\
5 & 23.949 & 0.020 & 0.042 \\
\hline
\end{tabular}

logger was used on each floor for measurements. In addition, one seismometer was used to observe the ambient vibration. Thus, a total of three data loggers were used. Fig. 11 shows all of them.

The measurement time was 600 seconds. Figs. 12 and 13 show closely the accelerometers positioned at the joints and their directions. Accelerometers are fixed to the joints with silicon. Then, it is aimed to fix it better by wrapping with special strong tapes.

The direction of the accelerometer is given in the accelerometer layout plan. The data obtained in these directions and measurement times are presented separately in each floor and in each channel. During the measurements, it was taken care not to create noise and during the measurement, there was no negative effect on the measurement area. The time to leave the area before the measurement was determined and the command to start the measurement was provided so that no noise was generated around the test apparatus during the measurement. The experimental setup is in the laboratory as shown in the figures. In this way, it has been tried to provide a more ideal measurement. Not only during the measurement, but also after

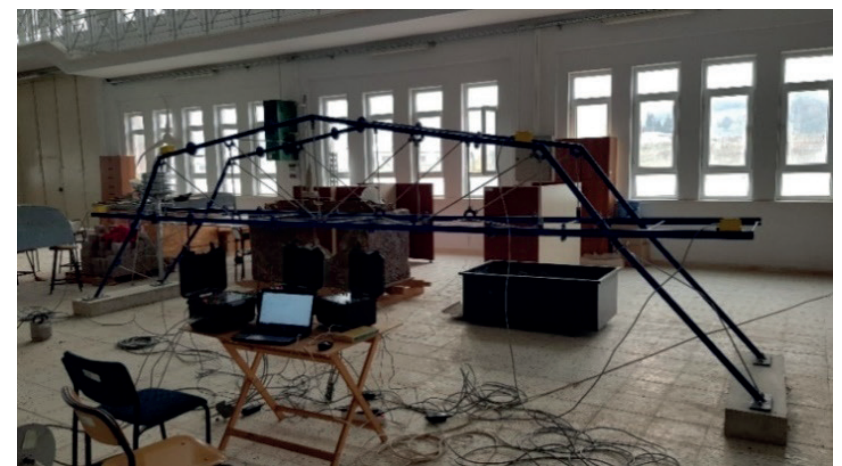

Fig. 11 Accelerometer placed on the model steel bridge

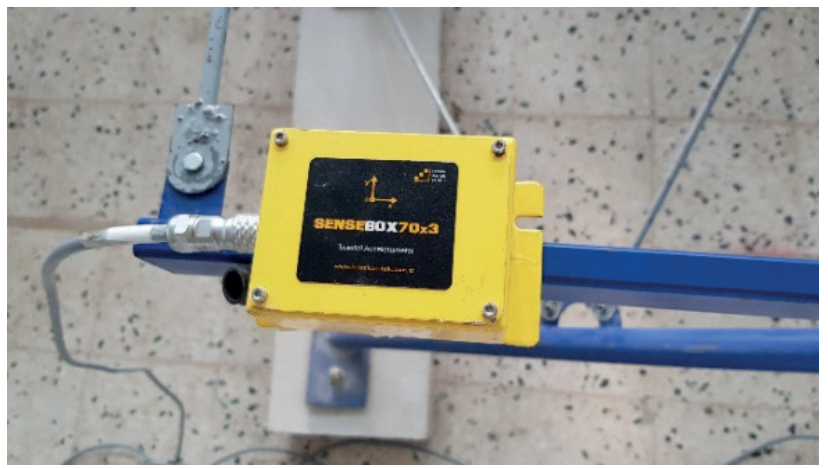

Fig. 12 Placing the triaxial accelerometer at the node

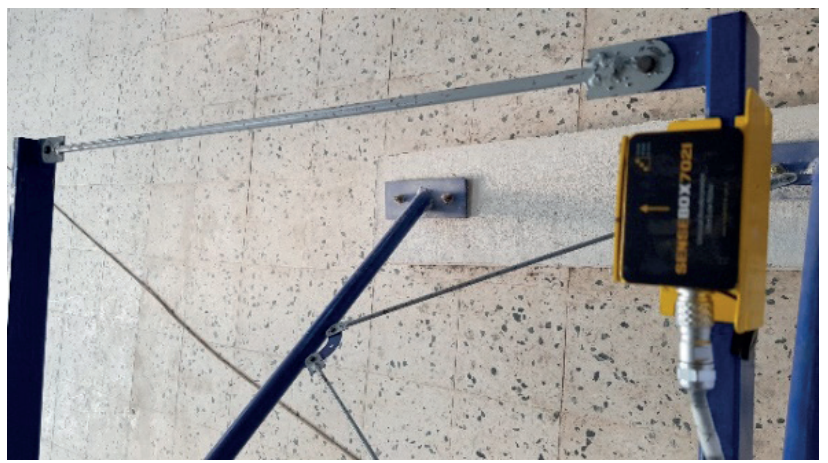

Fig. 13 Placing the uniaxial accelerometer at the node

the measurement, the data were reviewed and reliable data were obtained by repeating the measurements in any negative situation.

Singular values of spectral density matrices, attained from vibration data using SSI-PC technique is shown in Fig. 14. The first five mode shapes extracted from operational modal analyses are given in Figs. 15-19. When all measurements are examined, it can be seen that there is best accordance is found between experimental mode shapes. When the analytically and experimentally identified modal parameters are checked with each other, it can be seen that there is a best agreement between the mode shapes in operational and analytical modal analyses (Table 3). 


\section{Comparisons of dynamic characteristics}

Many criteria have been defined in the comparison of dynamic characteristics obtained from experimental measurements and analytical models [29].

These criteria are generally defined for modal shapes and commonly used criteria are Modal Scale Factor, Modal Assurance Criterion, Normalized Modal Difference.

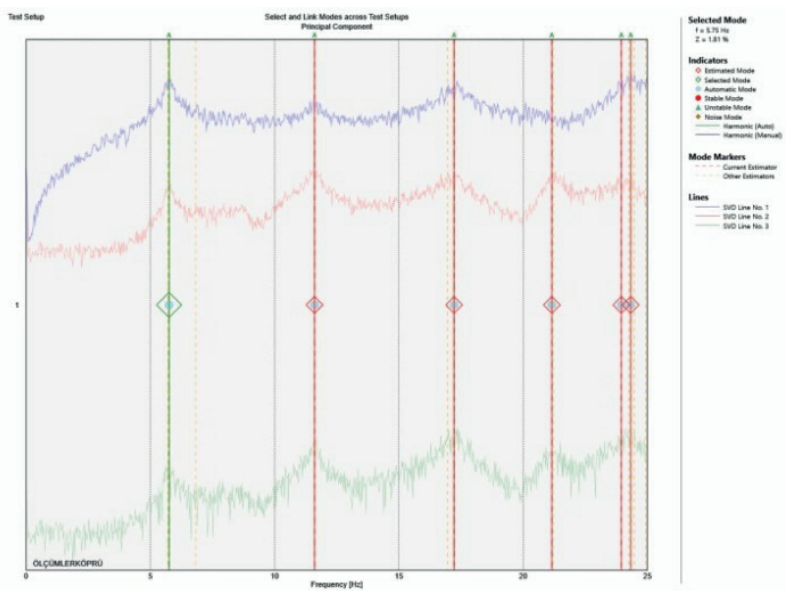

Fig. 14 SSI-PC Singular values of spectral density matrices

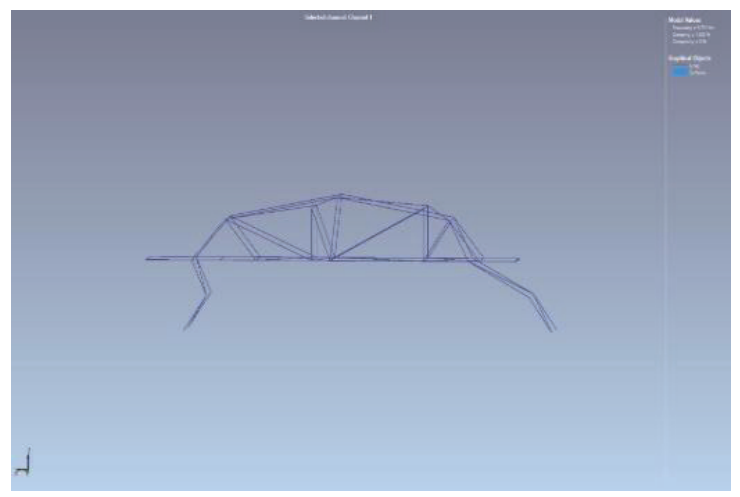

Fig. 151 st Mode shape SSI-PC $(f=5.751 \mathrm{~Hz}, T=0.173 \mathrm{~s}, \xi=0.018)$

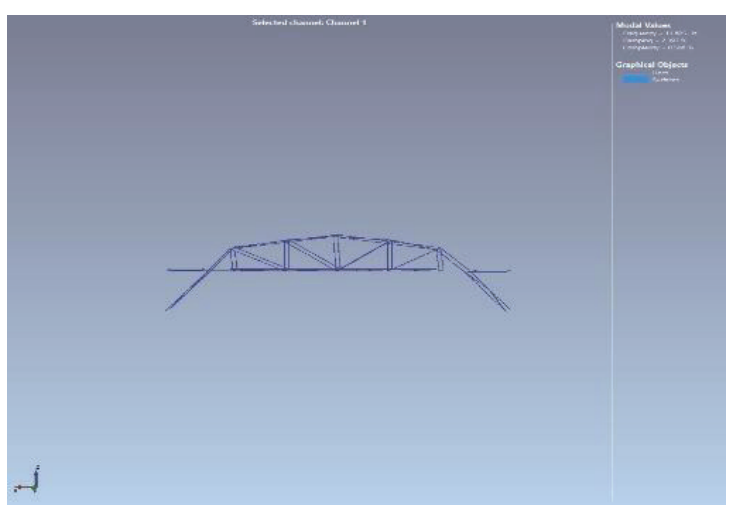

Fig. 16 2ndModeshapeSSI-PC $(f=11.605 \mathrm{~Hz}, T=0.086 \mathrm{~s}, \xi=0.024)$

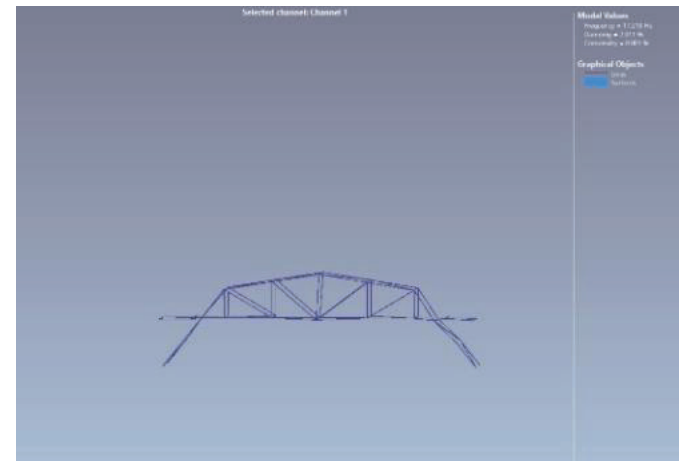

Fig. 17 3rd Mode shape SSI-PC $(f=17.219 \mathrm{~Hz}, T=0.058 \mathrm{~s}, \xi=0.020)$

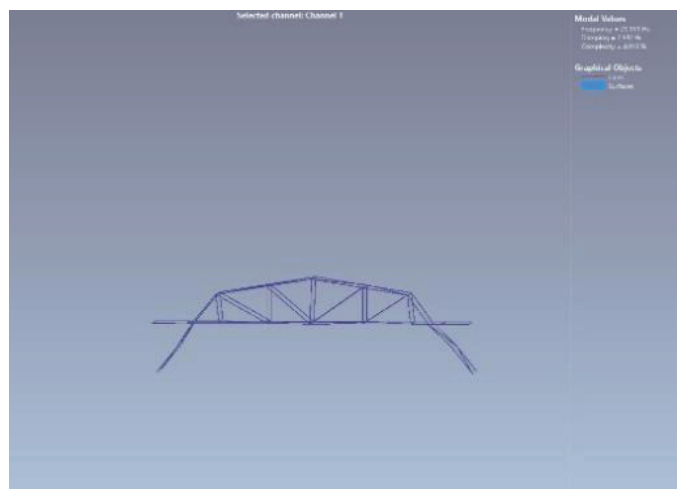

Fig. 184 th Mode shape SSI-PC $(f=21.151 \mathrm{~Hz}, T=0.047 \mathrm{~s}, \xi=0.026)$

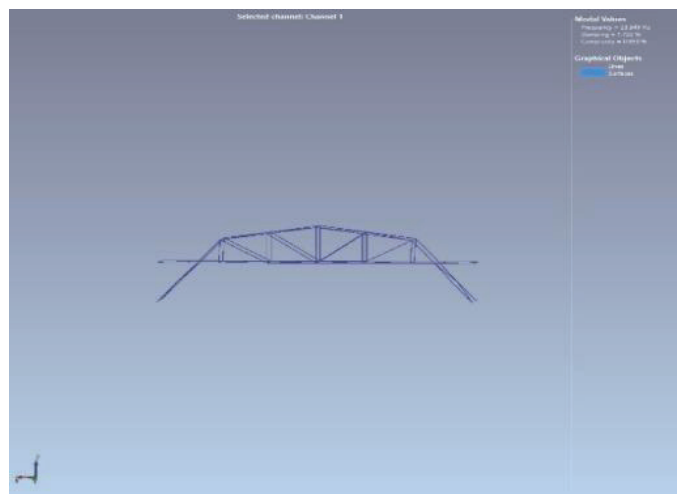

Fig. 195 th Mode shape SSI-PC $(f=21.151 \mathrm{~Hz}, T=0.047 \mathrm{~s}, \xi=0.026)$

Table 3 Comparison of analytical and operational modal analysis results

\begin{tabular}{lccccc}
\hline Mode number & 1 & 2 & 3 & 4 & 5 \\
\hline $\begin{array}{l}\text { Analytical } \\
\text { frequency (Hz) }\end{array}$ & 5.743 & 11.539 & 17.180 & 21.097 & 25.799 \\
$\begin{array}{l}\text { Operational } \\
\text { frequency (Hz) }\end{array}$ & 5.751 & 11.605 & 17.219 & 21.151 & 23.949 \\
\begin{tabular}{l} 
Difference (\%) \\
\hline
\end{tabular} & 0.139 & 0.571 & 0.227 & 0.256 & 7.170 \\
\hline
\end{tabular}

In this study, analytical natural frequencies based on experimental frequencies; mode shapes are mostly compared based on Modal Assurance Criteria values. 
$\left|\boldsymbol{f}_{k}-\boldsymbol{f}_{\cdot k}\right| \leq$ Specified limit of natural frequency difference

$\operatorname{MAC}\left(\boldsymbol{d}_{k}, \boldsymbol{d}_{\cdot k}\right)_{k=1, n} \geq \alpha$

$\left\{P_{\text {lower }}\right\} \leq\left\{P_{k}\right\} \leq\left\{P_{\text {upper }}\right\}$

Where $\boldsymbol{f}_{k}, \boldsymbol{f}_{\cdot k}$ are the current analytical and corresponding experimental values of the natural frequency, respectively; $\left\{P_{\text {lower }}\right\},\left\{P_{\text {upper }}\right\}$ are the lower and upper limits of the updating parameters, respectively; $\alpha$ is the lower limits of the matrix; $n$ is the compeered appropriate mode's number, another word it is the considered number of compeered degree of freedom of the structural system; $\operatorname{MAC}\left(\boldsymbol{d}_{k}, \boldsymbol{d}_{k k}\right)_{k=1, n}$ is the modal assurance criterion indices for between the FEA computational $\boldsymbol{d}_{k}$ and experimental $\boldsymbol{d}_{\cdot k}$ mode shapes, which indicate how well the FEA mode shapes fit to the corresponding measured ones and calculated as:

$\operatorname{MAC}\left(\boldsymbol{d}_{k}, \boldsymbol{d}_{\cdot k}\right)_{k=1, n}=\frac{\left(\sum_{j=1}^{n} \phi_{j k} \phi_{\cdot j k}\right)^{2}}{\sum_{j=1}^{n}\left(\phi_{j k}\right)^{2} \sum_{j=1}^{n}\left(\phi_{\cdot j k}\right)^{2}}$

In which $\phi_{j k}, \phi_{i j k}$ are the $j$-th coordinates of the $k$-th analytical and measured mode shapes, respectively. And the final to compare the mode shapes obtained from SSI and FEA methods, the mode assurance criterion (MAC) is used which is defined by the following equation:

Once all the conditions listed in Eqs. (11)-(14) are satisfied, the iteration process ends.

MAC matrix comparing a set of 5 modes. Red values are $100 \%$ MAC values. MAC matrix is given Fig. 20.

The first five mode shapes of the steel arch bridge model were extracted from these spectra and presented in Figs. 21-25. Also, a typical MAC graph for Finite Element

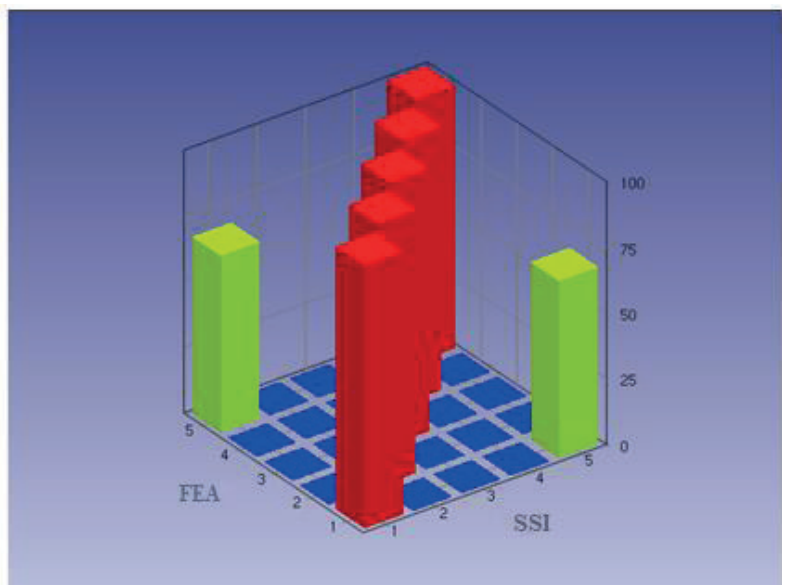

Fig. 20 3D plots of MAC matrix
Analysis (FEA) and SSI methods are given in Fig. 20. Fig. 20 shows that there are good agreements between mode shapes attained by FEA and SSI methods. The first five natural frequencies of the model steel arch bridge are given in Table 4 for each measurement duration. The tables include the modal damping ratios according to the frequency spans and the sampling rates. MAC matrix is given in Eq. (15).

$$
\mathrm{MAC}=\left[\begin{array}{ccccc}
100 & 0.0 & 0.0 & 0.0 & 67.2 \\
0.0 & 100 & 0.0 & 0.0 & 0.0 \\
0.0 & 0.0 & 100 & 0.0 & 0.0 \\
0.0 & 0.0 & 0.0 & 100 & 0.0 \\
67.2 & 0.0 & 0.0 & 0.0 & 100
\end{array}\right]
$$

The differences between the FEA and OMA modes and the matching of the modes are given in Table 4.

The pairing of the first 5 modes (Test Model-FEA Model) can be seen in Figs. 21-25.

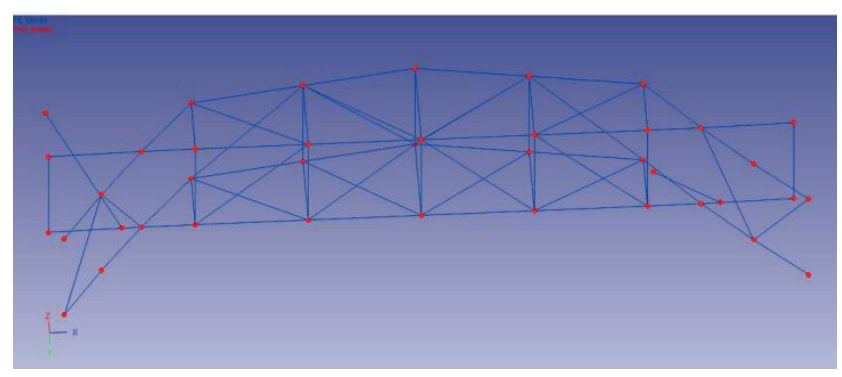

Fig. 21 FEA 1.Mode $(f=5.743 \mathrm{~Hz}, T=0.174 \mathrm{~s})$ - SSI-PC 1.Mode $(f=5.751 \mathrm{~Hz}, T=0.173 \mathrm{~s}, \xi=0.018)$

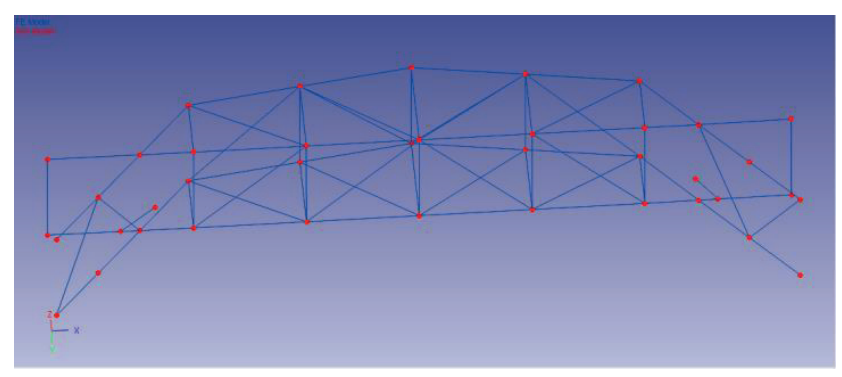

Fig. 22 FEA 2. Mode $(f=11.539 \mathrm{~Hz}, T=0.086 \mathrm{~s})$ - SSI-PC 2. Mode $(f=11.605 \mathrm{~Hz}, T=0.086 \mathrm{~s}, \xi=0.024)$

Table 4 FEA - OMA frequency differences and mode conflicts

\begin{tabular}{lcccccc}
\hline Figure & FEA & $\mathrm{Hz}$ & OMA & $\mathrm{Hz}$ & Diff. & MAC \\
\hline 20 & 1 & 5.74 & 1 & 5.75 & $-0,17$ & 100.0 \\
21 & 2 & 11.54 & 2 & 11.61 & $-0,61$ & 100.0 \\
22 & 3 & 17.18 & 3 & 17.22 & $-0,23$ & 100.0 \\
23 & 4 & 21.09 & 4 & 21.15 & $-0,28$ & 100.0 \\
24 & 5 & 25.79 & 5 & 23.95 & 7,14 & 100.0 \\
\hline
\end{tabular}




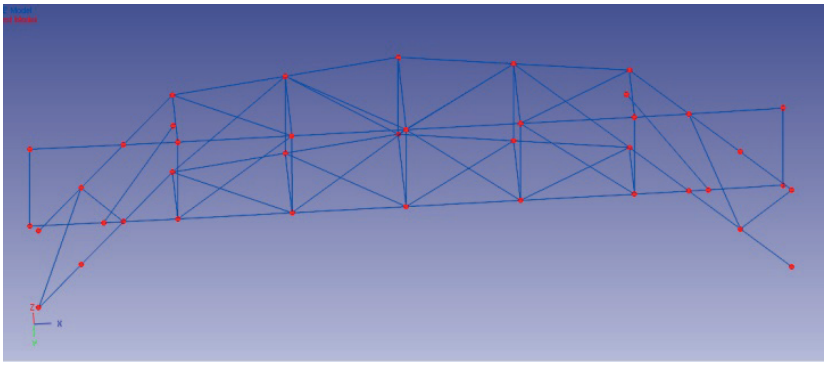

Fig. 23 FEA 3. Mode $(f=17.180 \mathrm{~Hz}, T=0.058 \mathrm{~s})$ - SSI-PC 3. Mode $(f=17,219 \mathrm{~Hz}, T=0.058 \mathrm{~s}, \xi=0.020)$

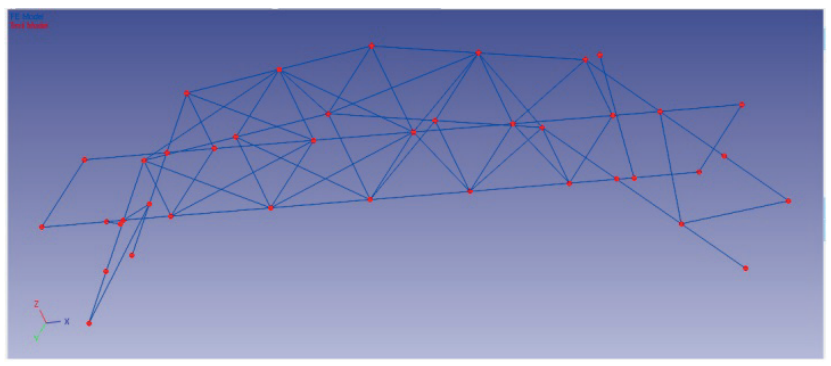

Fig. 24 FEA 4.Mode $(f=21.097 \mathrm{~Hz}, T=0.047 \mathrm{~s})$ - SSI-PC 4. Mode $(f=21.151 \mathrm{~Hz}, T=0.047 \mathrm{~s}, \xi=0.026)$

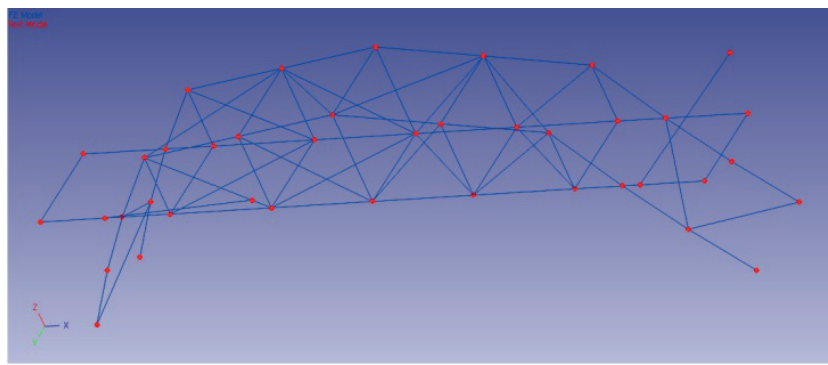

Fig. 25 FEA 5. Mode $(f=25.799 \mathrm{~Hz}, T=0,039 \mathrm{~s})-$ SSI-PC 5. Mode $(f=23.949 \mathrm{~Hz}, T=0.042 \mathrm{~s}, \xi=0.020)$

\section{Conclusions}

This kind of design bridge model has been created in order that the dynamic parameters obtained by using environmental vibration records in steel bridges are similar to the data obtained by the analytical model, thus contributing to the successful implementation and obtaining of dynamic parameters in the operational modal analysis, which is an innovative approach in steel arch bridges.

Objectively evaluating the structural conditions of real bridges can only be possible by determining local and global parameters based on measurement and determining structural parameters by combining them with the analytical model. It is recommended to pay attention to the following steps, especially in the evaluation of bridges of high strategic, material and vital importance. Based on measurement; objectively and repetitively over time to compare with analytical models and previous measurements;
Timely maintenance and strengthening works; It will be a pledge to avoid events that result in sad major destructions on the bridges.

In this paper, analytical and operational modal analysis of model steel arch bridge was presented. Comparing the result of study, the following observation can be made:

From the finite element model of model steel arch bridge a total of 5 natural frequencies were attained analytically, which range between 5 and $17 \mathrm{~Hz}$. 3D finite element model of model steel bridge is constructed with SAP2000 software and dynamic characteristics are determined analytically. The ambient vibration tests are conducted under provided from ambient vibration data on ground level. Modal parameter identification was implemented by the Stochastic Subspace Identification (SSI) technique. Comparing the result of analytically and operational modal analysis, the following observations can be made:

From the finite element model of the model steel arch bridge,

- The first five mode shapes are attained analytically that range between 5 and $17 \mathrm{~Hz}$.

- From the ambient vibration test, the first five natural frequencies are attained experimentally, which range between 5 and $23 \mathrm{~Hz}$.

- From the ambient vibration test, the damping ratios are attained experimentally, which range between $\xi=(0.018-0.020)$

When comparing the analytical and operational results, it is clearly seen that there is best agreement between mode shapes.

- Analytical and operational modal frequencies differences between $0.139 \%-7.170 \%$.

When modes are examined, it is clearly seen that mode 1 is translational in $\mathrm{X}$ direction, mode 2 is translational in $\mathrm{Y}$ direction and mode 3 is torsion. The modal assurance criterion (MAC) was used as a mathematical tool for the verification of the mode shapes of natural vibrations obtained in experimental and numerical ways.

Good compatibility was recognized between the results obtained for experimental and numerical procedures in terms of both the natural frequency and the mode of vibration.

Under the light of all these findings, modal parameters model of the steel arch bridge under the influence of ambient vibration were determined by SSI-PC method. It is known that the obtained parameters are more reliable than theoretical methods in terms of representing the real values. Therefore, the obtained modal parameters better represent the steel arch bridge. 


\section{References}

[1] Natke, H. G., Cempel, C. "Model-Aided Diagnosis of Mechanical Systems", Springer, Berlin, Germany, 1997.

https://doi.org/10.1007/978-3-642-60413-3

[2] Matsumoto, Y., Yamaguchi, H., Yoshioka, T. "A field investigation of vibration-based structural health monitoring in a steel truss bridge", In: ABSE-JSCE Joint Conference on Advances in Bridge Engineering-II, Dhaka, Banglades, 2010, pp. 461-467. [online] Available at: http://iabse-bd.org/old/26.pdf

[3] Kvåle, K. A., Øiseth, O., Rønnquist, A. "Operational modal analysis of an end-supported pontoon bridge", Engineering Structures, 148, pp. 410-423, 2017.

https://doi.org/10.1016/j.engstruct.2017.06.069

[4] Cantieni, R. "Experimental Methods Used in System Identification of Civil Engineering Structures", presented at $2^{\circ}$ Workshop: Problemi di vibrazioni nelle strutture civili e nelle costruzioni meccaniche (2nd Workshop: Vibration Problems in Civil Structures and Mechanical cConstructions), Perugia, Italy, June, 10-11, 2004.

[5] Gentile, C. "Modal and structural identification of a R.C. arch bridge", Structural Engineering and Mechanics, 22(1), pp. 53-70, 2006 .

https://doi.org/10.12989/sem.2006.22.1.053

[6] Sanayei, M., DiCarlo, C. "Finite Element Model Updating of Scale Bridge Model Using Measured Modal Response Data", presented at Structures Congress, Austin, TX, USA, Apr. 30 - May, 2, 2009. https://doi.org/10.1061/41031(341)11

[7] Yang, C. "Seismic analysis of long span bridges including the effects of spatial variation of seismic waves on bridges", PhD Thesis, Hong Kong University of Science and Technology, 2007. https://doi.org/10.14711/thesis-b987465

[8] Aydin, H. "Obtaining Modal Parameters in Steel Model Bridge by System Identification Using Artificial Neural Networks", International Journal of Trend in Scientific Research and Development, 4(2), pp. 438-443, 2020. [online] Available at: https://www.ijtsrd.com/papers/ijtsrd30013.pdf

[9] Ren, W.-X., Zhao, T., Harik, I. E. "Experimental and Analytical Modal Analysis of Steel Arch Bridge", Journal of Structural Engineering, 130(7), pp. 1022-1031, 2004. https://doi.org/10.1061/(ASCE)0733-9445(2004)130:7(1022)

[10] Türer, A., Kaya, H. "Köprülerin Yapisal Özelliklerinin Dinamik Ölçümler Ve Modal Analiz İle Belirlenmesi", Middle East Technical University, Department of Civil Engineering, Ankara, 2010. (in Turkish)

[11] Kasımzade, A., Tuhta, S., Aydın, H., Günday, F. "Determination of Modal Parameters on Steel Model Bridge Using Operational Modal Analysis", presented at 8th International Steel Structures Symposium, Konya, Turkey, Oct. 24-26, 2019.

[12] Kasimzade, A. A., Tuhta, S. "Particularities of monitoring, identification, model updating hierarchy in experimental vibration analysis of structures", presented at EVACES'07: Experimental Vibration Analysis for Civil Engineering Structures, Porto, Portugal, Oct. 24-26, 2007.

[13] Kasimzade, A. A., Tuhta, S. "Optimal estimation the building system characteristics for modal identification", presented at IOMAC 2009 - 3rd International Operational Modal Analysis Conference, Portonovo, Italy, May, 4-6, 2009.
[14] Peeters, B. "System identification and damage detection in civil engineering", PhD Dissertation, KU Leuven, 2000.

[15] Computers and Structures Inc. "SAP2000, (v19)", [computer program] Available at: https://www.csiamerica.com/products/ sap2000 [Accessed: 20 January 2021]

[16] Sidhu, J., Ewins, D. J. "Correlation of Finite Element and Modal Test Studies of a Practical Structure", presented at 2nd International Modal Analysis Conference \& Exhibit, Orlando, FL, USA, Feb. 6-9, 1984.

[17] Tuhta, S., Günday, F., Aydın, H. "Dynamic Analysis of Model Steel Structures Retrofitted with GFRP Composites under Microtremor Vibration", International Journal of Trend in Scientific Research and Development, 3(2), pp. 729-733, 2019. https://doi.org/10.31142/ijtsrd21455

[18] Tuhta, S., Günday, F., Aydın, H. "Numerical Algorithms for System Identification of Benchmark Steel Bridge", In: ISTE-CE'2019International Conference on Innovation, Sustainability, Technology and Education in Civil Engineering, Iskenderun, Turkey, 2019, pp. 1223-1237.

[19] Akrami, V., Majid, Z. S. "Enhanced least square complex frequency method for operational modal analysis of noisy data", Earthquakes and Structures, 15(3), pp. 263-273, 2018. https://doi.org/10.12989/eas.2018.15.3.263

[20] Van Overschee, P., De Moor, B. "Subspace Identification for Linear Systems, Theory - Implementation - Applications", Springer, Boston, MA, USA, 1996. https://doi.org/10.1007/978-1-4613-0465-4

[21] Fukumoto, Y., Takewaki, I. "Critical earthquake input energy to connected building structures using impulse input", Earthquakes and Structures, 9(6), pp. 1133-1152, 2015. https://doi.org/10.12989/eas.2015.9.6.1133

[22] Tang, Z., Xie, X., Wang, T. "Residual seismic performance of steel bridges under earthquake sequence", Earthquakes and Structures, 11(4), pp. 649-664, 2016. https://doi.org/10.12989/eas.2016.11.4.649

[23] Simon, J., Vigh, L. G., Horváth, A., Pusztai, P. "Application and Assessment of Equivalent Linear Analysis Method for Conceptual Seismic Retrofit Design of Háros M0 Highway Bridge", Periodica Polytechnica Civil Engineering, 59(2), 109-122, 2015. https://doi.org/10.3311/PPci.7860

[24] Huszár, Z., Hegedűs, I. "Free Vibrations of a Paraboloid Shell", Periodica Polytechnica Civil Engineering, 49(1), pp. 13-26, 2005. [online] Available at: https://pp.bme.hu/ci/article/view/569/326

[25] Kasimzade, A. A., Tuhta, S. "Stochastic Parametric System Identification Approach for Validation of Finite Element Models: Industrial Applications", TWMS Journal of Pure and Applied Mathematics, 3(1), pp. 41-61, 2012.

[26] Kasımzade, A., Tuhta, S., Aydın, H., Günday, F. "Investigation of Modal Parameters on Steel Model Bridge Using EFDD Method", In: Proceedings on 2nd International Conference on Technology and Science, Burdur, Turkey, 2019, pp. 140-149.

[27] Tuhta, S., Aydın, H., Günday, F. "Updating for Structural Parameter Identification of the Model Steel Bridge Using OMA", International Journal of Latest Technology in Engineering, Management \&Applied Science (IJLTEMAS), 9(3), pp. 59-68, 2020. [online] Available at: https://www.ijltemas.in/DigitalLibrary/Vol.9Issue3/59-68.pdf 
[28] Türkeli, E. "Dynamic Seismic and Wind Response of Masonry Minarets", Periodica Polytechnica Civil Engineering, 64(2), pp. 353-369, 2020. https://doi.org/10.3311/PPci.15035

[29] Tuhta, S. "Optimal Determination of Structural Dynamical Parameters Using Ambient Vibration", Kahramanmaraş Sütçü İmam Üniversitesi Mühendislik Bilimleri Dergisi, 21(1), pp. 55-65, 2018. https://doi.org/10.17780/ksujes.344989

[30] Structural Vibration Solutions "ARTeMIS Extractor", [computer program] Available at: https://svibs.com/ [Accessed: 20 January 2021]

[31] Giraldo, D. F. "A Structural Health Monitoring Framework for Civil Structures", PhD Thesis, Washington University the Henry Edwin Server Graduate School Department of Civil Engineering, 2006.

[32] Kasımzade, A. A., Tuhta, S. "Application of OMA on the BenchScale Earthquake Simulator Using Micro Tremor Data", Structural Engineering and Mechanics, 61(2), pp. 267-274, 2017. https://doi.org/10.12989/sem.2017.61.2.267

[33] Tuhta, S., Günday, F., Aydın, H., Alalou, M. "Modal analysis of model steel bridge by finite element method", presented at 2nd International Eurasian Conference on Science, Engineering and Technology, Gaziantep, Turkey, Oct. 15-17, 2020.
[34] Tuhta, S., Günday, F., Aydın, H. "Update of Structural Parameters on the Bench-Scale Aluminum Bridge Model Using Ambient Vibration", International Journal of Latest Technology in Engineering, Management \& Applied Science, 9(4), pp. 10-18, 2020.

[35] Tuhta, S., Günday, F., Aydın, H. "System Identification of Model Steel Bridge with Fuzzy Logic", International Journal of Research and Innovation in Applied Science, 5(1), pp. 50-54, 2020.

[36] Tuhta, S., Günday, F., Aydın, H. "System Identification of Model Steel Bridge with Genetic Algorithms", International Journal of Research and Innovation in Applied Science, 5(1), pp. 55-59, 2020.

[37] Günday, F. "OMA of RC Industrial Building Retrofitted with CFRP using SSI", International Journal of Advance Engineering and Research Development, 5(5), pp. 759-771, 2018.

[38] Günday, F. "GFRP Retrofitting Effect on the Dynamic Characteristics of Model Steel Structure Using SSI", International Journal of Advance Engineering and Research Development, 5(4), pp. 11601173, 2018.

[39] Tuhta, S. "GFRP retrofitting effect on the dynamic characteristics of model steel structure", Steel and Composite Structures, 28(2), pp. 223-231, 2018.

https://doi.org/10.12989/SCS.2018.28.2.223 